\title{
Communication
}

\section{Conformal Coating by Liquid Route on Three- Dimensional Topology}

\author{
Poirot Nathalie ${ }^{1,2, *}$ and Raynal Pierre-Ivan ${ }^{2}$ \\ 1 GREMAN-IUT de Blois, 15 rue de la Chocolaterie, 41000 Blois cedex France; nathalie.poirot@univ-tours.fr \\ 2 Departement Microscopies, 10, bd Tonnellé - B.P. 3223 Université de Tours, 37032 TOURS Cedex; pierre- \\ ivan.raynal@univ-tours.fr \\ * Correspondence: nathalie.poirot@univ-tours.fr; Tel.: +33-254-552-197
}

\begin{abstract}
We demonstrated a new approach to the production of three-dimensional-coated patterns using liquid route. Metallic perovskite oxides were coated onto three-dimensional (3D) microstructured substrates with different aspect ratios. The success of the method relies on the solution viscosity monitored by adding viscous liquid. The process of oxide thin films consists in three steps: preparing the precursor solution, coating the solution by spin-coating process onto three-dimensional-Si substrates and post-annealing. The chemical solution 3D-coating is conformal.
\end{abstract}

Keywords: nanostructures; thin films; 3D-coating

\section{Introduction}

The Over the last few years the development of miniaturized power sources and the diversification of devices, has increased the need of three-dimensional (3D) integration. As an example, components such as Metal/Insulator/Metal (MIM) and Micro-Electro-Mechanical-Systems have been developed with 3D integration to be embedded into chips. Theses 3D- developed components have also been widely developed for applications such as Dynamic Random Access Memory [1-3] optical or Radio-frequency (RF) switches [4-6]. The benefits of 3D architectures are the reductions in size, cost, and the increase in reliability and energy related performance.

Moreover 3D structuring enhances the physical properties of devices. Therefore research in this area is extremely active, particularly in the fields of micro-batteries, supercapacitors, fuel cells, solar cells [7-19]. A significant breakthrough was achieved by Golodnitsky [10], in the field of Li-ion microbatteries by reaching a reversible capacity of $3.5 \mathrm{~mA} \cdot \mathrm{h} / \mathrm{cm}^{2}$. This is about 20 to 30 times superior to the two-dimensional (2D) thin films capacity. In the area of RF applications, the integration of functions requires more complex grouping of active and passive components.

Current deposition techniques for growing thin films on 3D substrates are divided in two categories: physical and chemical. Physical techniques consist in Physical Vapor Deposition (PVD), vacuum evaporation, molecular beam epitaxy and sputtering. These techniques require combining work (high voltage, vacuum, etc.) and low deposition rates (close to $10 \mathrm{~nm} \cdot \mathrm{min}^{-1}$ ). Chemical techniques consist in electro-deposition by electrophoresis, Chemical Vapor Deposition, the plasma activated chemical vapor deposition, Plasma-Enhanced Chemical Vapor Deposition, atomic layer depostion (ALD).

When deposing complex perovskite-type oxides films in high aspect ratios 3D structures, the conventional liquid route becomes inefficient: the capillary process increases proportionally with the aspect ratio, which is defined by the etching depth divided by the trench width. In order to obtain a good coating on the 3D micro-structured substrates with a high aspect ratio, the viscosity control of deposit solution is the critical parameter.

To monitor the solution viscosity the concentration is the only parameter to be adjusted. Indeed, the capillary process follows the Jurin law (Equation 1): 


$$
h=\frac{2 \gamma \cos \theta}{r \rho g}
$$

where $\mathrm{h}$ is the liquid height, $\gamma$ is the liquid surface tension, $\theta$ is the liquid contact angle on the substrate, $\mathrm{Q}$ is solution density, $\mathrm{r}$ is tube radius and $\mathrm{g}$ is gravitational acceleration.

The contact angle must be controlled by the solvent choice and/or by the addition of additives allowing good wettability with silicon (Si) substrates.

In this paper, we demonstrate how controlling the solution viscosity before coating makes 3D conformal liquid coating on Si substrates efficient whatever the aspect ratio are.

We report the preparation of $\mathrm{LaNiO}_{3}$ (LNO) films on 3D-Si substrates. LNO component has been chosen because of their good electrical conductivity. It could be used as bottom and top electrodes in MIM, electrodes in ferroelectric devices and in integrated capacitors or buffer layers [20-25]. A chemical solution deposition process has been selected to prepare LNO thin films. Until now, the deposit of LNO thin film prepared by chemical solution deposition process in 3D substrates has rarely been successfully investigated.

The obtained results demonstrate that chemical solution deposition on 3D micro-structured substrates with high aspect ratios enable efficient coating.

\section{Materials and Methods}

\subsection{Characterization}

The solution viscosity is checked by a Brookfield viscometer (LVD-III) with cone spindle. The morphology of coated films is characterized using scanning electron microscopy (SEM) whereas Xray diffraction (XRD) (Bruker D8 Advanced model with twin-twin type) is used for structural analysis. Thermogravimetric analyses (Perkin Elmer Diamond thermogravimetry (TG) and differential thermal analysis (DTA)) of dried precursors are performed at a ramp rate of $10^{\circ} \mathrm{C} \cdot \mathrm{min}^{-1}$ from room temperature to $1000{ }^{\circ} \mathrm{C}$, using $\alpha-\mathrm{Al}_{2} \mathrm{O}_{3}$ as a reference. Resistivity measurements on films are carried out using the four probe method. SEM micrographs with high magnification are obtained on a Zeiss ultra plus field emission guns (FEG)-SEM at an accelerating voltage of $2 \mathrm{kV}$ with a secondary electrons InLens detector, with a work distance of about 2-3 mm.

\subsection{Methods}

The method consists of simply dissolving the metallo-organic compounds in solvents $[23,24]$. No hydrolysis of precursors is observed, the species in solution are a simple mixture of starting molecules. Following the four steps below:

1- The precursors are dissolved in a suitable solvent and mixed in stoichiometric proportions

2- The obtained solution is coated on a substrate by spin-coating.

3- To remove the solvent and produce an inorganic film a thermal process is applied to the asdeposited film

4- The samples are annealed at a temperature up to the oxide crystallization temperature.

Precursors are tetra-hydrated lanthanum nitrate (Sigma Aldrich, $\mathrm{La}\left(\mathrm{NO}_{3}\right)_{3}, 6 \mathrm{H}_{2} \mathrm{O}, 99.9 \%$ ) and nickel acetate (Sigma Aldrich, $\mathrm{Ni}\left(\mathrm{OOCCH}_{3}\right)_{2}, 4 \mathrm{H}_{2} \mathrm{O}, 99.9 \%$ ), the solvent is 2-methoxyethanol (Sigma Aldrich, $\mathrm{C}_{3} \mathrm{H}_{8} \mathrm{O}_{2}$, 99.9\%). Glycerol (Sigma Aldrich, 99-101 \% purity) and poly(ethylene glycol) (PEG) -10 000 (Sigma Aldrich) are added to the LNO solution to adjust the viscosity. The prepared concentrations without PEG and glycerol are $0.15 \mathrm{M}, 0.3 \mathrm{M}$ and $0.5 \mathrm{M}$. The solvent choice is essential to obtain a dense thin film. The 2-methoxyethanol solvent has been selected for two reasons. The first is the presence of glycol groups that allow a strong affinity with metal atoms of tetrahydrated lanthanum nitrate and nickel acetate so a good combination with $\mathrm{La}^{3+}$ and $\mathrm{Ni}^{2+}$ atoms is obtained. As a result, no precipitation is observed during the solvent evaporation. The second is the high wettability of 2-methoxyethanol on ( $\mathrm{Si}$ ) substrates.

To synthesize precursor solution, the lanthanum nitrate is dissolved in the solvent preheated to $100{ }^{\circ} \mathrm{C}$ to evaporate residual water under constant stirring. When maintaining heating at $80-90^{\circ} \mathrm{C}$, the 
solution becomes clear. An equimolar amount of nickel acetate is then added. After 30 minutes of stirring, the solution becomes homogeneous. The viscosity values increase with concentration. The values are respectively $2.8 \mathrm{mPa} \cdot \mathrm{s}, 4.41 \mathrm{mPa} \cdot \mathrm{s}$ and $9.8 \mathrm{mPa} \cdot \mathrm{s}$.

The solutions with addition of PEG or glycerol have a mass ratio (mLNO solution/madjuvant) that varies from 1 to 4 . The respective viscosity values are then close to $40 \mathrm{mPa} \cdot \mathrm{s} \sim 85 \mathrm{mPa} \cdot \mathrm{s}$.

The same procedure has been used by A. Vincent et al. for precursors solutions preparation with polyester addition and not PEG or glycerol [26]. For adjust the viscosity, M. Gabard et al. have add to Si nanoparticles the same polymer [27].

\subsection{Substrate Preparation}

The Si (110) substrates are trenched using the STiger [28] or the standard cryogenic etching [29] processes. Trenches and vias with different aspect ratios are thus obtained. SEM pictures of typical high-aspect-ratio trenches produced through the standard cryogenic etching are shown in figure 1.
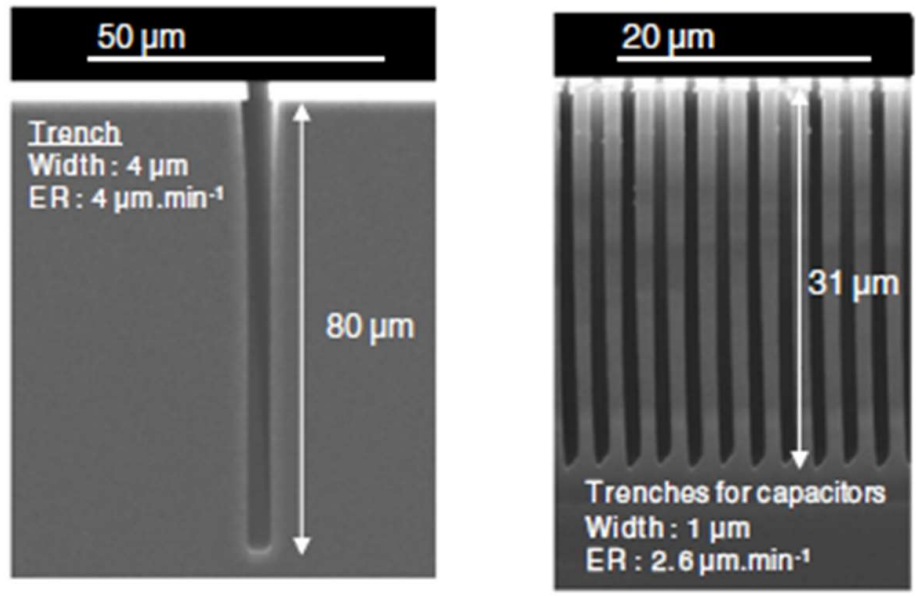

Figure 1. Cross-sectionnal SEM micrograph of typical trench profiles obtained in silicon cryoetching (see ref. Dussart 2014)).

The cleaning of the Si substrate before coating is realized in two steps:

1- removal of chemical residues through in HF solution

2- the Radio Corporation of America (RCA) method [31]. The Si substrates are then introduced over a 10 minute period in a mixture of $\mathrm{H}_{2} \mathrm{O}, \mathrm{H}_{2} \mathrm{O}_{2}$ and $\mathrm{NH}_{4} \mathrm{OH}$ with a volumetric ratio of 5:1:1 and heated at about $75-80^{\circ} \mathrm{C}$.

\subsection{Coating Process}

The coatings on clean Si substrates are performed using spin-coating with a ramp rate of 2000 $\mathrm{rpm} / \mathrm{s}$ and a spin speed of $3000 \mathrm{rpm}$ for 30s. $150 \mu \mathrm{L}$ of solution are deposited on etched Si substrates.

After the coating, all samples obtained are heated in air at precisely defined temperatures following three steps.

1- Drying at $175^{\circ} \mathrm{C}$ on a hot plate for 2 minutes allows solvent evaporation.

2- Pyrolyzing at $375^{\circ} \mathrm{C}$ on a hot plate for 3 minutes to remove the metal-organic matrix.

3- Calcination of films inserted directly into a furnace preheated at $700{ }^{\circ} \mathrm{C}$ with a dwell of 20 min to crystallize and densify the films (rapid thermal annealing (RTA) process).

To determine the required temperatures, the thermal behaviors of solutions have been studied. In figure 2, percentage weight loss with temperature is shown for glycerol, PEG and $\mathrm{LaNiO}_{3}$ solutions. The data indicate that the glycerol and PEG have decomposition temperatures respectively close to $180{ }^{\circ} \mathrm{C}$ and $250{ }^{\circ} \mathrm{C}$, while the 2-methoxyethanol is decomposed above $200{ }^{\circ} \mathrm{C}$. LNO crystallization temperature is about $650^{\circ} \mathrm{C}$. In the third heating step, thermal process is called RTA although it is not a "true" RTA where the ramp temperature can be close to $100{ }^{\circ} \mathrm{C} / \mathrm{s}$. 


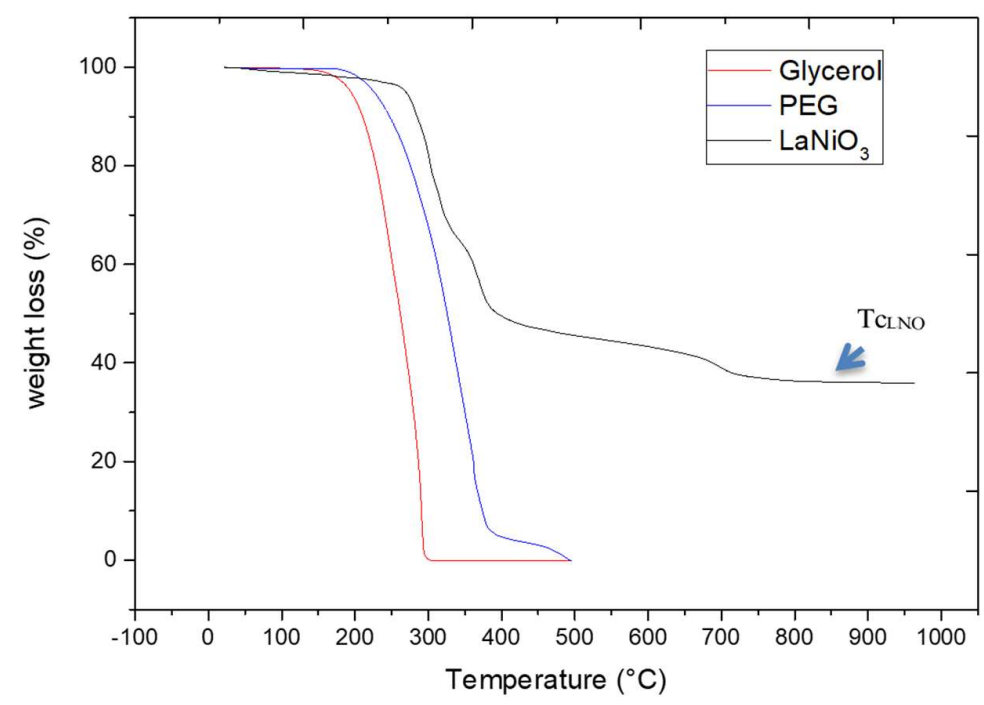

Figure 2. Thermal analysis of $\mathrm{LaNiO}_{3}$ solution, glycerol and PEG. TcLNo $=$ crystallisation temperature of LNO.

Two major benefits of the RTA step are:

1- the limitation of the diffusion phenomena to the interface

2- the film densification without cracks.

The complete process must be repeated as many times as the desired number of layers.

\section{Results and Discussion}

Three methods have been used to coat $\mathrm{LaNiO}_{3}$ thin film in 3D-substrate. We report here the results of each of them.

\subsection{Coating Non-Modified $\mathrm{LaNiO}_{3}$ Chemical Solution}

Stable precursor chemical solution of $\mathrm{LaNiO}_{3}$ has first prepared and coated according to previously reported chemical solution deposition processes. A single coated layer has been deposited, the solution viscosity being about $9.8 \mathrm{mPa} \cdot \mathrm{s}$ and with $0.5 \mathrm{M}$ LNO concentration. The crosssectionnal SEM micrograph of LNO film on Si substrate is shown in figure 3. The LNO layer is dense but many cracks are observed. The film thickness is not the same from the bottom to the top of the trench. Non-covered parts, accumulations of products and the formation of filaments in the trenches are observed. These defects were systematically observed for a coated-solution viscosity value below $10 \mathrm{mPa} \cdot \mathrm{s}$. , whatever the precursor concentrations were.

As described by R. Seemannet al., the wetting of microstructured surfaces relies on many factors. From these work, a global morphology diagram is derived (see figure 4) [31]. For high aspect ratios as in our case, the system corresponds to the filament regime (F-) with a negative Laplace pressure. The cross-sectionnal SEM micrograph for a coating with $0.15 \mathrm{M} \mathrm{LNO}$ solution with high aspect ratios (8) is shown in figure 4c. The filaments are well visible. The higher the aspect ratios are, the more complex uniform trenches coating becomes. As stated by reference 29, a homogeneous coating is impossible on geometries showing breaks of angles. As indicated before, the capillary force follows the Jurin's law. The solution viscosity is one of the parameters that can be modified to reduce the capillary force and therefore obtain uniform coating in trenches. Consequently, the solution viscosity must be increased. Then, PEG and glycerol have been add in LNO solution, with good wettability of chemical solution to Si substrate for coating LNO film. 


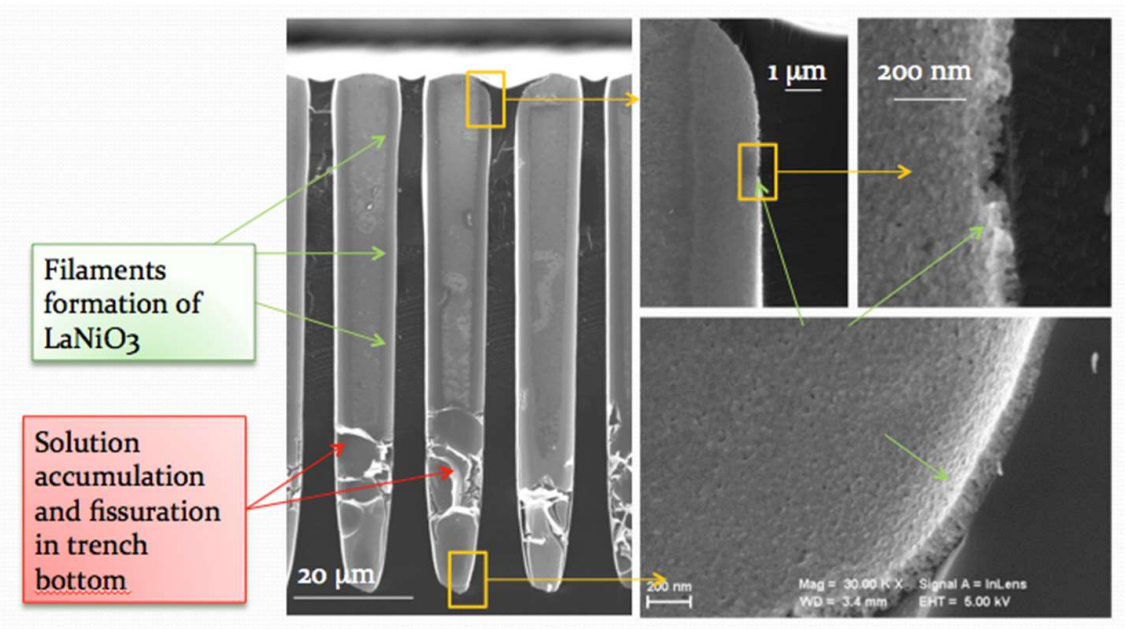

Figure 3. Cross-sectionnal SEM micrograph of a $\mathrm{LaNiO}_{3}$ coating in trench with a $0.5 \mathrm{M}$.

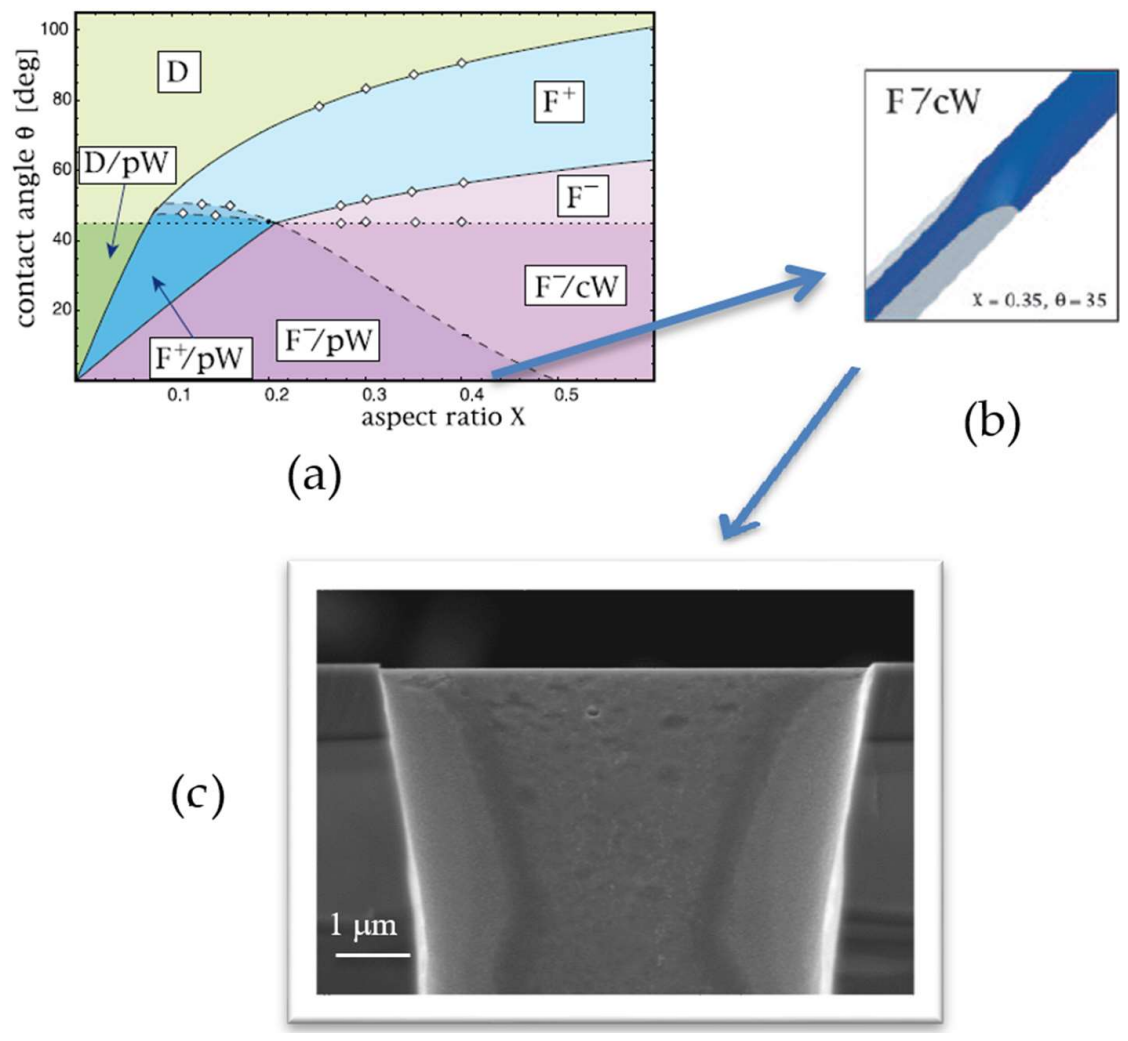

Figure 4. Morphology diagram as a function of groove aspect ratio $X$ (a) and material contact angle $\theta$ (b), reproduced with permission from Seemann [31]. Key: =/- = Laplace pressure, F=Filament, $\mathrm{cw}=$ corner wedges, $\mathrm{D}=$ droplet, $\mathrm{pw}=$ pinned wedges. Cross-sectionnal SEM micrograph for a coating with a $0.15 \mathrm{M}$ LNO solution with high aspect ratio of 8 .

\subsection{Coating Modified $\mathrm{LaNiO}_{3}$ Chemical Solution with Viscosity Values below $70 \mathrm{mPa} \cdot \mathrm{s}$.}

Consequently, new stable precursor chemical solutions of $\mathrm{LaNiO}_{3}$ have been prepared as previously described with addition of glycerol or PEG to obtain viscosity values between 40 to 70 $\mathrm{mPa} \cdot \mathrm{s}$. Figure 5 shows the cross-sectionnal SEM micrograph for one deposited layer with $0.3 \mathrm{M}$ (LNO+ PEG) solution concentration. The aspect ratio is 8 and the viscosity value is $40 \mathrm{mPa} \cdot \mathrm{s}$. 

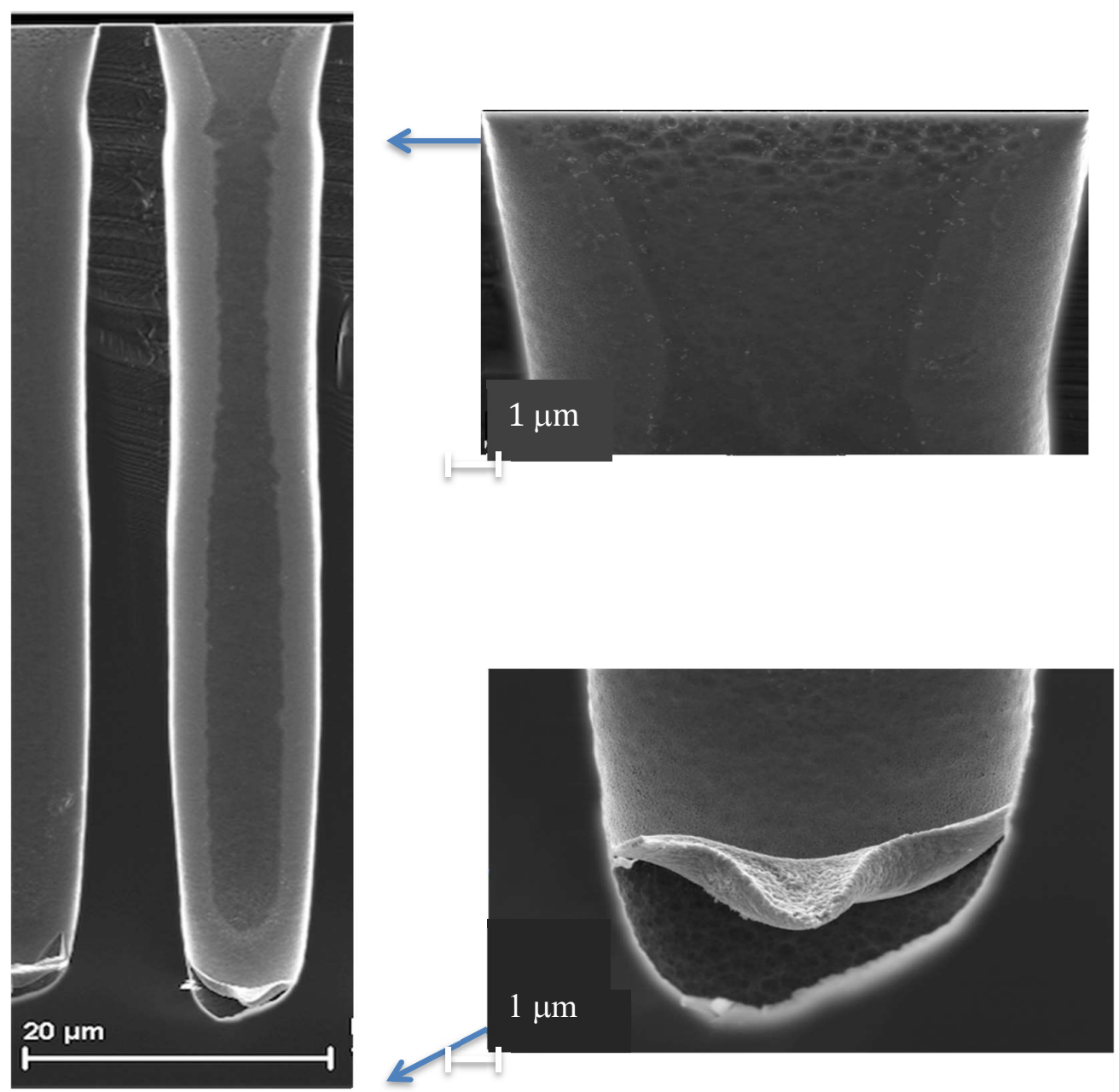

Figure 5. Cross-sectionnal SEM micrograph of (0.3M LNO solution + PEG ) coating with a viscosity value of $40 \mathrm{mPa} \cdot \mathrm{s}$.

Cracks are observed in the trench bottom and the trench walls are non-uniformly covered with a formation of filaments. The middle trench walls are generally not covered by oxide material. Whatever the concentration value and the mass ratio (mLNO solution/madjuvant) are, the same results are observed when the viscosity value is down to $70 \mathrm{mPa} \cdot \mathrm{s}$. Our results confirm the morphology diagram published by Seemann et al.[31] and reported in Figure 4.

\subsection{Coating Modified $\mathrm{LaNiO}_{3}$ Chemical Solution with Viscosity Values above $70 \mathrm{mPa} \cdot \mathrm{s}$}

The solution viscosity was increased by modifying of the mass ratio between LNO solution and adjuvant. A new stable and homogeneous mixture with $1 \mathrm{~mL}$ of $0.6 \mathrm{M} \mathrm{LNO}$ and $1 \mathrm{~mL}$ of PEG has been prepared. The viscosity value is close to $85 \mathrm{mPa} \cdot \mathrm{s}$. A single layer has been coated on trenched $\mathrm{Si}$ substrate with an aspect ratio close to 3 . The cross-sectionnal SEM micrograph are shown in figure 6. No cracks and no filaments as predicted by Y.WI et al. [21] were observed and the LNO material was dense. The bottom trench was well covered with a LNO thickness close to $45 \mathrm{~nm}$. The coating is homogeneous with precipitation on the trenches. As a comparison, the LNO thickness on 2D surface is close to $31 \mathrm{~nm}$ with the same LNO concentration solution. 


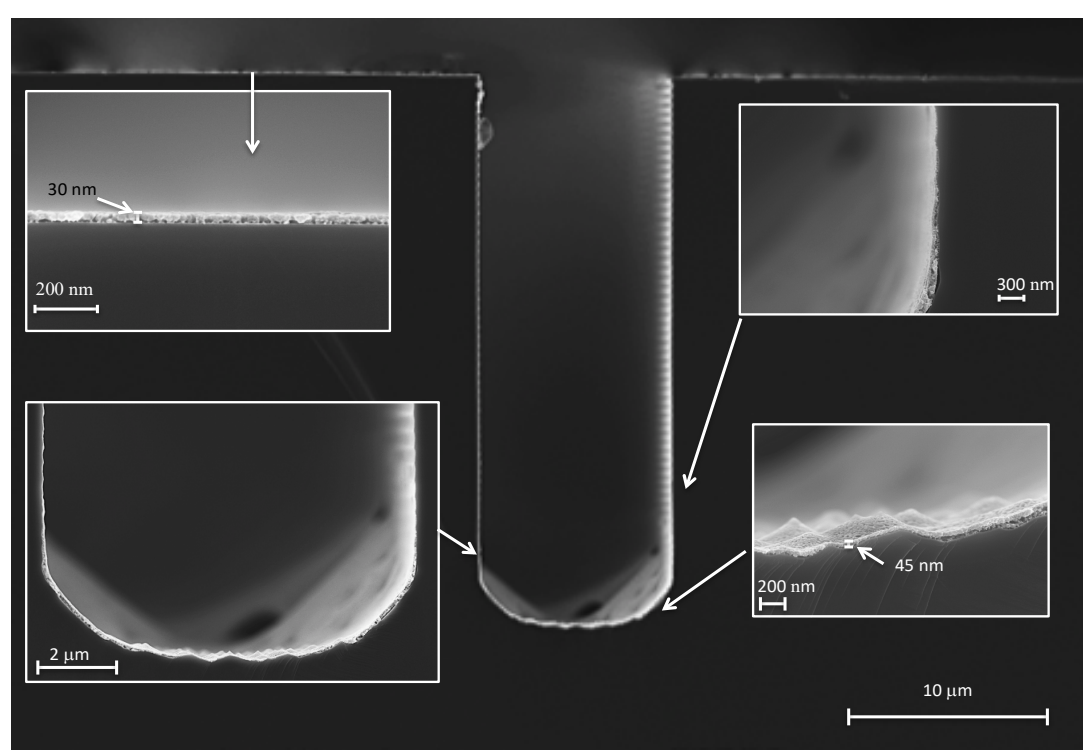

Figure 6. Cross-sectionnal SEM micrograph obtained from a layer of a ( $1 \mathrm{~mL}$ PEG $+1 \mathrm{~mL} 0.6 \mathrm{M} \mathrm{LNO})$ solution. The aspect ratio is 3 .

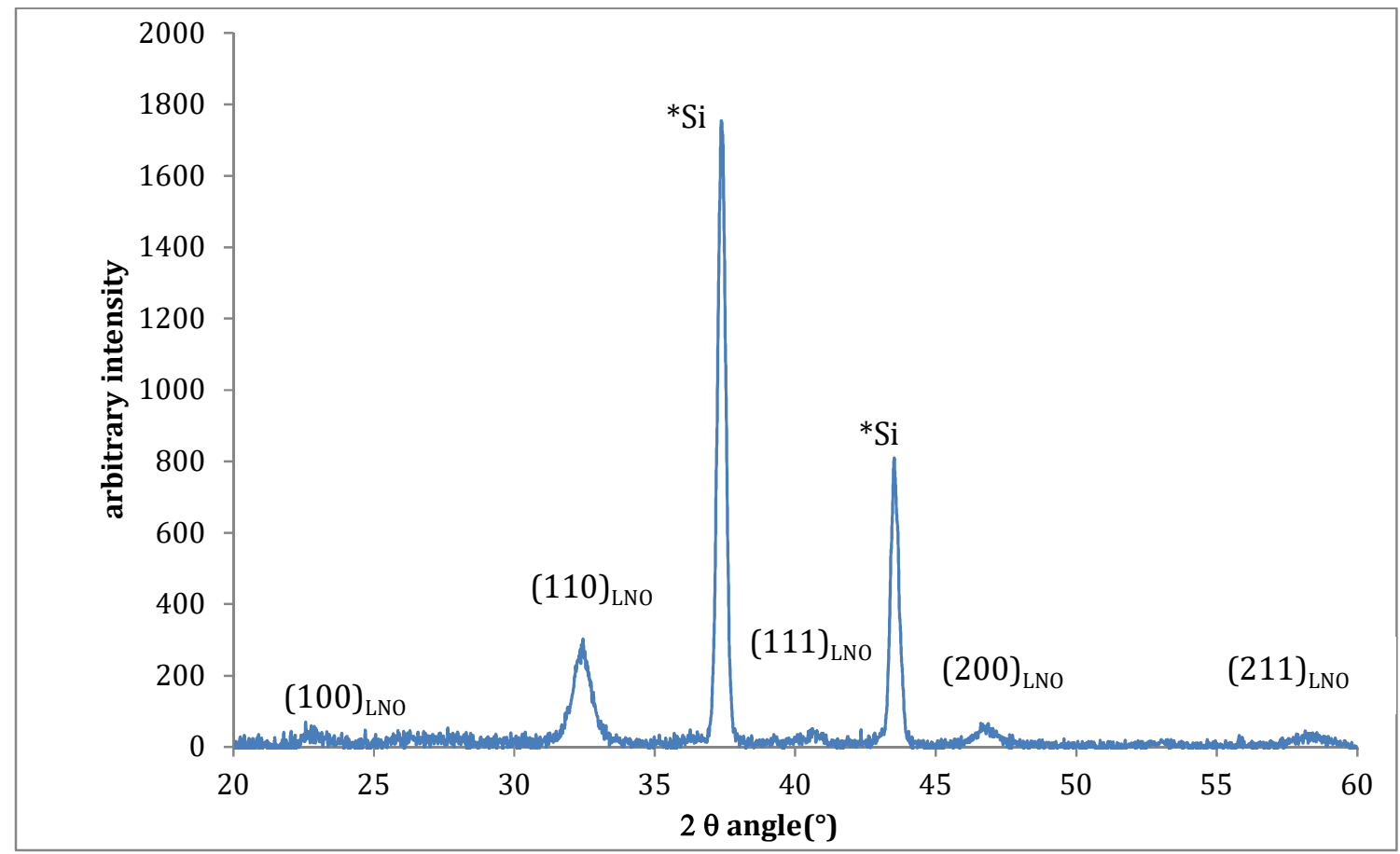

Figure 7. DRX on LNO films grown following a preferred orientation along (110).

It should be noted that the layer thickness changes together with the LNO solution concentration independently of glycerol or PEG add. The electrical resistivity of 3D LNO film is about $2.4 \mathrm{m \odot .cm}$, a value close to those measured for the 2D LNO thin films. Figure 7 shows the XRD pattern of LNO thin film. An oriented growth along (110) direction is found. This orientation was kept layer by layer as long as each deposited layer remains thicker than $100 \mathrm{~nm}$ [32]. The addition of PEG did not affect the LNO oriented growth.

To validate this process, multi-layers coating has been experienced. A mixture was prepared with a $0.3 \mathrm{M}$ LNO solution and PEG with a mass ratio close to 1 . The solution viscosity was about $80-$ $85 \mathrm{mPa} \cdot \mathrm{s}$.. Three layers have been coated on Si substrate with an aspect ratio about 10. The SEM results are shown in figure 8. 


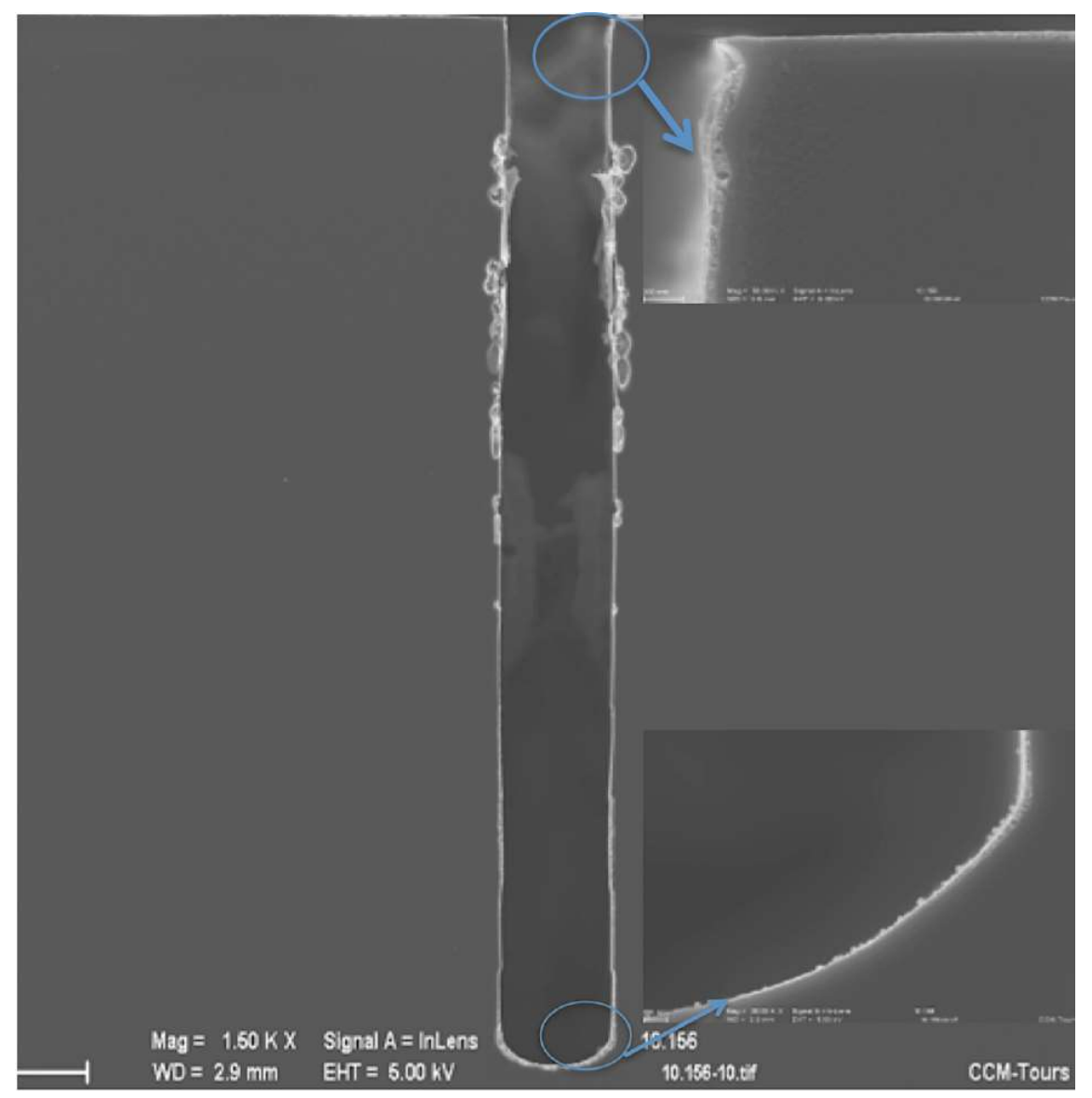

Figure 8 . Cross-sectionnal SEM micrograph obtained from 3 layers of a $0.3 \mathrm{M}$ (PEG + LNO) solution heating at $700{ }^{\circ} \mathrm{C}$. The $\mathrm{Si}$ aspect ration is 10 .

The coating is uniform and no cracks are observed. Many defects are observed: they do not related to the coating process. Indeed, when cutting Si substrate, ceramic pieces residues have fallen in the trenches. Figure 8 shows that successive LNO layers with no defects can be obtained when the viscosity value is about $80-85 \mathrm{mPa} \cdot \mathrm{s}$.

Another solution mixture has been studied: $1 \mathrm{~mL}$ of $0.6 \mathrm{M}$ LNO solution mixed with $1 \mathrm{~mL}$ of glycerol. The viscosity was close to $80 \mathrm{mPa} \cdot \mathrm{s}$. After homogenization of the mixture, the system has been deposited on substrates with an aspect ratio about 3 in a single layer. Figure 9 shows the crosssectionnal SEM micrograph. The thin films are porous due to decomposition of glycerol. As consequently, the electrical conductivity could not be measured. The 3D-substrate is recovered with LNO ceramic with a thickness close to $200 \mathrm{~nm}$. Edges are well covered too with regular thickness. The bottom trenches show an irregular surface but are also well covered. As a conclusion, the cover is uniform.

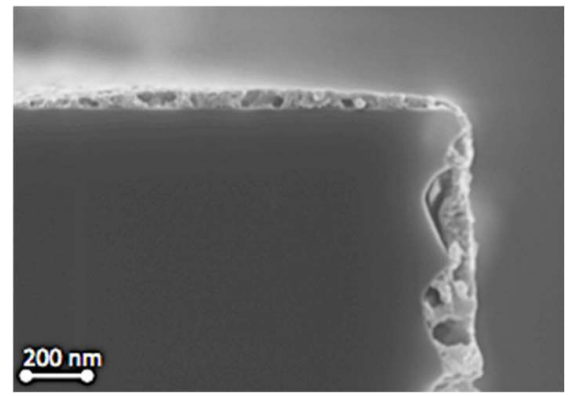

(a)

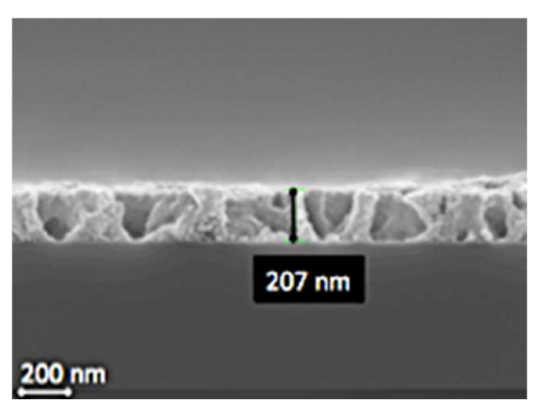

(b) 


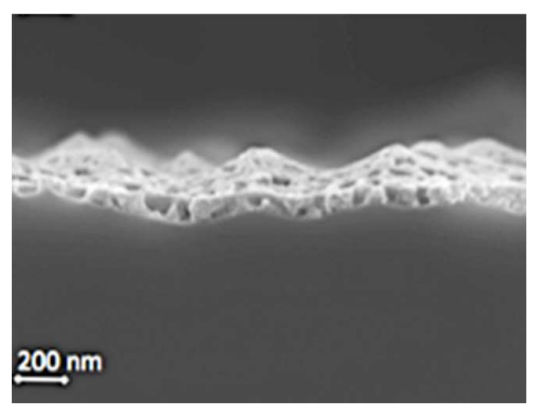

(c)

Figure 9. Cross-sectionnal SEM micrograph obtained with a (Glycerol +LNO) mixture for a single deposited layer. (a): image on the edge of the trench, (b) image of the layer on the surface, (c) image in the trench bottom.

Table 1 synthesizes the results obtained when changing the various parameters: adjuvant used, viscosity level, aspect ratio, number of coated layers.

Table 1. Coating quality according to different parameters.

\begin{tabular}{ccccccc}
\hline $\begin{array}{c}\text { Solution } \\
\text { concentration }\end{array}$ & $\begin{array}{c}\text { Adjuvant } \\
\text { used }\end{array}$ & Viscosity & $\begin{array}{c}\text { Aspect } \\
\text { ratio }\end{array}$ & $\begin{array}{c}\text { Layers } \\
\text { number }\end{array}$ & $\begin{array}{c}\text { Coating } \\
\text { quality }\end{array}$ & $\begin{array}{c}\text { Figure } \\
\text { number }\end{array}$ \\
0,5 & None & 9,8 & 9 & 1 & None & 3 \\
0,3 & None & 2,8 & 8 & 1 & None & 4 \\
0,6 & PEG & 39 & 8 & 1 & None & 5 \\
0,3 & PEG & 85 & 3 & 1 & Good & 6 \\
0,6 & PEG & 85 & 10 & 3 & Good & 8 \\
\hline
\end{tabular}

\section{Conclusions}

We demonstrate that coating chemical solutions in 3D microstructured substrates is possible without going through expensive techniques, as PVD or CVD by example. A control of solution viscosity is necessary with a good wettability of solution on Si substrate and a solution well homogeneous. Table 1 synthesizes the results obtained when changing the various parameters: adjuvant used, viscosity level, aspect ratio, number of coated layers.

Our experimental results demonstrate that the solution viscosity control is the essential parameter to obtain uniform coating on 3D micro-structured substrates with various aspect ratios.

Moreover, our experience highlights a new coating method for complex oxides deposited on 3Dstructured substrates. Our process is less complex and expensive than the physical (PVD) and chemical (ALD) ones. Indeed, this one combines chemical solution synthesis with spin-coating deposition, shows the following advantages: high solution stability, good wettability with Si substrates, simple, speed and low cost. This process does not require high vacuum and high temperature levels.

The key success factors of this process are:

1- a solution viscosity value equal to or greater than $80 \mathrm{mPa} \cdot \mathrm{s}$.

2- the heating of the substrates up to $350{ }^{\circ} \mathrm{C}$ without degradation.

3- a large choice of materials can be used:

- for 3D structured substrates: Ceramics $\left(\mathrm{Al}_{2} \mathrm{O}_{3}\right.$, Yttria-stabilized zirconia, etc.), metals $(\mathrm{Ni}, \mathrm{Fe}$, etc.), semiconductors (Si, etc.), glass (silica), or mixtures (ceramics, composites, etc.), solar cells.

- for deposited oxides: $\mathrm{TiO}_{2}, \mathrm{~V}_{2} \mathrm{O}_{5}, \mathrm{RuO}_{2}, \mathrm{CoO}_{2}, \mathrm{NiO}, \mathrm{ZnO}, \mathrm{CeO}_{2}, \mathrm{ABO}_{3}$ perovskite, $\mathrm{A}_{2} \mathrm{BO}_{4}$ double-perovskite, etc.

This new coating method opens a new perspective in 3D integrated devices as biomedical implants, sensors or integrated circuits and small size integrated batteries. By enlarging the specific 
surface, 3D-integrated devices offer high level physical properties compared to 2D-integrated devices. The advantages of the developed process are simplicity, speed, not expensive cost, not high vacuum and high temperature levels not required in comparison with the classical coating thin films methods.

\section{Author Contributions:}

Acknowledgments: This research project was supported through funding from the ANR (French National Research Agency).

Conflicts of Interest: The authors declare no conflict of interest.

\section{References}

1. J.H. Klootwij, K.B. Jinesh, W. Dekkers, J.F. Verhoeven, F.C. Van den Heuvel, H.D. Kim, D. Blin, M.A. Verheijen, R.G.R Weemaes, M. Kaiser, J. Ruigrok, F. Roozeboom, Ultrahigh Capacitance Density for Multiple ALD-Grown MIM Capacitor Stacks in 3-D Silicon, IEEE, Electron device letters (2008) 29, 740-742, DOI: 10.1109/LED.2008.923205

2. B.L. Ellis, P. Knauth, T. Djenizian, Three-Dimensional self-supported metal oxides for advanced energy storage, Adv. Mater. (2014) 26, 3368-3397, DOI: 10.1002/adma.201306126.

3. J.H. Klootwijk, K.B. Jinesh, F. Roozeboom, MIM in 3D: Dream or reality? Engineering (2011) 8, 1507-1513, doi.org/10.1016/j.mee.2011.03.137.

4. J.B. Bates, N.J. Dudney, D.C. Lubben, G.R. Gruzalski, B.S. Kwak, X. Yu, R.A. Zuhr, Thin-film rechargeable lithium batteries J. doi.org/10.1016/0378-7753(94)02040-A

5. J.F.M. Oudenhoven, L. Bagetto, P.H.L. Notten, All-Solid-State Lithium-Ion Microbatteries: A Review of Various Three-Dimensional Concepts Adv. Energy Mat. (2011) 1, 10-33, DOI: 10.1002/aenm.201000002.

6. J.F.M. Oudenhoven, T. van Dongen, R.A.H. Niessen, M.H.J.M. de Croon, P.H.L. Notten, Low-Pressure Chemical Vapor Deposition of LiCoO2 Thin Films: A Systematic Investigation of the Deposition Parameters, J. Electrochem. Soc. (2009) 156, 69-174, doi: 10.1149/1.3082374.

7. L. Bagetto, R.A.H Niessen, F. Roozeboom, P.H.L.Notten, High energy density all-solid-state batteries: a challenging concept towards 3D integration, Avd. Funct. Mater. (2008) 18, 1057-1066, doi.org/10.1002/adfm.200701245.

8. E. Eustache, P. Tilmant, L. Morgenroth, P. Roussel, G. Patriarche, D.Troadec, N. Rolland, T. Brousse, C. Lethien, Silicon-Microtube Scaffold Decorated with Anatase TiO2 as a Negative Electrode for a 3D LitiumIon Microbattery, Adv. Energy Mater. (2014) 1301612, doi: 10.1002/aenm.201301612

9. H. Mazor, D. Golodnitsky, L. Burstein, A. Gladkich, E. Peled, Electrophoretic deposition of lithium iron phosphate cathode for thin-film 3D-microbatteries, Journal of Power Sources (2012) 198, 264-272, doi:10.1016/j.jpowsour.2011.09.108.

10. D. Golodnitsky, M. Nathan, V. Yufit, E. Strauss, K. Freedman, L. Burstein, A. Gladkich, E. Peled, Progress in three-dimensional (3D) Li-ion microbatteries, Solid Ionics State (2006) 177, 2811-2819, doi:10.1016/j.ssi.2006.02.048.

11. T. Liu, H. Zhang, F. Wang, J. Shi, P. Ci, L. Wang, L. Ge, S.Q. Wang, P.K. Chu, Three dimensional supercapacitors composed of $\mathrm{Ba} 0.65 \mathrm{Sr} 0.35 \mathrm{TiO} 3$ (BST)/NiSi2/silicon microchannel plates, Mat. Sci.Eng. B. (2011) 176, 387-392, doi:10.1016/j.mseb.2010.12.008.

12. C. Zhang, Y. Song, M. Wang, M. Yin, L. Tian, H.Wang, X. Chen, Z. Fan, L. Lu, D. Li, Efficient and Flexible Thin Film Amorphous Silicon Solar Cells on Nanotextured Polymer Substrate Using Sol-gel Based Nanoimprinting Method, Adv. Funct. Mater. (2017) 27, 1604720, doi.org/10.1002/adfm.201604720

13. K. Qiu, D. Qiu, L. Cai, S. Li, W. Wu, Z. Liang, H. Shen, Preparation of ZnS thin films and ZnS/p-Si heterojunction solar cells, Materials Letters (2017) 198, 23-26, doi.org/10.1016/j.matlet.2017.03.171

14. S. Ferrari, M. Loveridge, S.D. Beattie, M. Jahn, R.J. Dashwood, R. Bhagat, Latest advances in the manufacturing of 3D rechargeable lithium Microbatteries, Journal of Power Sources (2015) 286, 25-46, doi.org/10.1016/j.jpowsour.2015.03.133

15. S. Nohren, E. Quiroga-Gonzalez, J. Carstensen, Helmut Foll, Electrochemical Fabrication and Characterization of Silicon Microwire Anodes for Li Ion Batteries Journal of The Electrochemical Society (2016) 163, A373-A379, DOI: 10.1149/2.0111603jes 
16. H. Porthault, F. Le Cras, J.M. Duffault, S. Franger, Fast depositionofconformalLiCoO2 thin filmelectrodesforhigh capacity 3Dbatteries, Mat. Sci. and Eng. B (2016) 213, 163-168, doi.org/10.1016/j.mseb.2016.05.001

17. E. Eustache, C. Douard, A. Demortière, V. De Andrade, M. Brachet, J.Le Bideau, T. Brousse, C. Lethien, High Areal Energy 3D-Interdigitated Micro-Supercapacitors in Aqueous and Ionic Liquid Electrolytes, Adv. Mater. Technol. (2017), 1700126, DOI: 10.1002/admt.201700126

18. M. Létiche, E. Eustache, J. Freixas, A. Demortière, V. De Andrade, L. Morgenroth, P. Tilmant, F. Vaurette, D. Troadec, P. Roussel, T. Brousse, C. Lethien, Atomic Layer Deposition of Functional Layers for on Chip 3D Li-Ion All Solid State Microbattery, Adv. Energy Mater. (2017) 7, 1601402, DOI: 10.1002/aenm.201601402

19. N. A. Kyeremateng, T. Brousse, D. Pech, Microsupercapacitors as miniaturized energy-storage components for on-chip electronics, Nature technology (2017),12, DOI: 10.1038/NNANO.2016.196

20. W.J. Lin, X. Qi, G. Chern, J.C.A. Huang, Epitaxial growth and exchange coupling of spinel ferrimagnet Ni0.3Zn0.7Fe2O4 on multiferroic BiFeO3, Thin Solid Films (2011) 519, 8326-8329, doi:10.1016/j.tsf.2011.03.068.

21. Y.W. Li, Z.G. Hu, J.L. Sun, X.J. Meng, J.H. Chu, Effects of LaNiO3 bottom electrode on structural and dielectric properties of CaCu3Ti4O12 films fabricated by sol-gel method, Appl. Phys. Lett. (2008) 92, 042901-042904, doi.org/10.1063/1.2837534.

22. G.P. Mambrini, E.R. Leite, M.T. Escote, A.J. Chiquito, E. Longo, J.A. Varela, R.F. Jardim, Structural, microstructural, and transport properties of highly oriented LaNiO3 thin films deposited on $\mathrm{SrTiO} 3$ (100) single crystal, J. Appl. Phys. (2007) 102, 043708-043714, doi.org/10.1063/1.2769349.

23. R.W. Schwartz, Chemical Solution Deposition of Perovskite Thin films, American Chemical Society (1997) 9, 2325-2340, doi:10.1016/j.crci.2004.01.007.

24. X. Meng, J. Cheng, J. Sun, H. Ye, S. Guo, J. Chu, Growth of (1 0 0)-oriented LaNiO3 thin films directly on Si substrates by a simple metalorganic decomposition technique for the highly oriented PZT thin films, Journal of Crystal Growth (2000) 220, 100-104, doi.org/10.1016/S0169-4332(00)00537-7.

25. H. Miyazaki, T. Goto, Y. Miwa, T. Ohno, H. Suzuki, T. Ota, M. Takahashi, Preparation and evaluation of $\mathrm{LaNiO}_{3}$ thin film electrode with chemical solution deposition, Journal of the European Ceramic Society (2004) 24, 1005-1008, doi:10.1016/S0955-2219(03)00382-0.

26. A. Vincent, N. Poirot, Method depositing an inorganic material on a substrate, in particular a micron - or subsmicron -scale textured substrate (2014), WO/2015/044582.

27. Marie Gabard, Mustapha Zaghrioui, David Chouteau, Virginie Grimal, Thomas Tillocher, Fouad Ghamouss, Nathalie Poirot, Novel Method Based on Spin-Coating for the Preparation of 2D and 3D SiBased Anodes for Lithium Ion Batteries, Chem Engineering (2017) 1, 5, doi:10.3390/chemengineering1010005

28. T. Tillocher, W. Kafrouni, J. Ladroue, P. Lefaucheux, M. Boufnichel, P. Ranson, R. Dussart, Optimization of submicron deep trench profiles with the STiGer cryoetching process: reduction of defects, J. Micromechanics \& Microengineering (2011) 21, 085005-085014, doi:10.1088/0960-1317/21/8/085005.

29. R. Dussart, T. Tillocher, P. Lefaucheux, M. Boufnichel, Plasma cryogenic etching of silicon: from the early days to today's advanced technologies, Phys. D: Appl. Phys. (2014) 47, 123001-123028, doi:10.1088/0022$3727 / 47 / 12 / 123001$.

30. W. Kern, The Evolution of Silicon Wafer Cleaning Technology, J. Electrochem. Soc. (1990) 137, 1887-1892.

31. R. Seemann, M. Brinkmann, E.J. Kramer, F.F. Lange, R. Lipowsky, Wetting morphologies at microstructured surfaces, PNAS (2005) 102, 1848-1852, doi_10.1073_pnas.0407721102.

32. Y. Guo, D. Akai, K. Sawada, M. Ishida, Dielectric and ferroelectric properties of highly (100)-oriented ( $\mathrm{Na} 0.5 \mathrm{Bi} 0.5) 0.94 \mathrm{Ba} 0.06 \mathrm{TiO} 3$ thin films grown on $\mathrm{LaNiO} / \mathrm{g}-\mathrm{Al} 2 \mathrm{O} 3 / \mathrm{Si}$ substrates by chemical solution deposition, Solid State Sciences (2008) 10, 928-933, doi:10.1016/j.solidstatesciences.2007.10.026. 